IZA DP No. 9657

Gender Differences in Altruism:

Responses to a Natural Disaster

Matthew Lilley

Robert Slonim

January 2016

Forschungsinstitut zur Zukunft der Arbeit Institute for the Study of Labor 


\title{
Gender Differences in Altruism: Responses to a Natural Disaster
}

\author{
Matthew Lilley \\ University of Sydney \\ and Harvard University \\ Robert Slonim \\ University of Sydney \\ and IZA
}

Discussion Paper No. 9657
January 2016

IZA

P.O. Box 7240

53072 Bonn

Germany

Phone: +49-228-3894-0

Fax: +49-228-3894-180

E-mail: iza@iza.org

\begin{abstract}
Any opinions expressed here are those of the author(s) and not those of IZA. Research published in this series may include views on policy, but the institute itself takes no institutional policy positions. The IZA research network is committed to the IZA Guiding Principles of Research Integrity.

The Institute for the Study of Labor (IZA) in Bonn is a local and virtual international research center and a place of communication between science, politics and business. IZA is an independent nonprofit organization supported by Deutsche Post Foundation. The center is associated with the University of Bonn and offers a stimulating research environment through its international network, workshops and conferences, data service, project support, research visits and doctoral program. IZA engages in (i) original and internationally competitive research in all fields of labor economics, (ii) development of policy concepts, and (iii) dissemination of research results and concepts to the interested public.
\end{abstract}

IZA Discussion Papers often represent preliminary work and are circulated to encourage discussion. Citation of such a paper should account for its provisional character. A revised version may be available directly from the author. 


\section{ABSTRACT \\ Gender Differences in Altruism: Responses to a Natural Disaster}

High-profile disasters can cause large spikes in philanthropy and volunteerism. By providing temporary positive shocks to the altruism of donors, these natural experiments help identify heterogeneity in the distributions of the latent altruism which motivates donors. This study examines gender heterogeneity of volunteer response by blood donors following the most devastating Bushfires in Australia's history. Using difference in differences analyses, we observe a sharp increase in blood donations after the 2009 Victorian Bushfires. Several key features of this increase are consistent with the predictions of a model where the distribution of latent altruism has smaller variance among women than men. First, the highest increase in donations occurs among previous non-donors, lapsed donors and less frequent donors. Further, the increase in donations following the Bushfires, compared to non-disaster periods, is substantially greater for females than males; the proportional increase in the number of females donating for the first time after the disaster is approximately twice the proportional increase for men. Notably, this gender gap decreases with the frequency with which people have previously donated.

JEL Classification: D64, C93

Keywords: gender, natural experiment, altruism

Corresponding author:

Robert L. Slonim

Faculty of Arts and Social Sciences

HO4 - Merewether

University of Sydney

Sydney, NSW 2006

Australia

E-mail: robert.slonim@sydney.edu.au

\footnotetext{
* We greatly appreciate financial support from the Science of Philanthropy Initiative, the Templeton Foundation and the Australian Research Council, Discovery Product Grant \#1095222, and the Australian Red Cross Blood Service (Blood Service) for their continuous support. We appreciate comments on an earlier draft from Michelle Bergmann, Ashley Craig, Stephanie Heger, Andrew Lilley, Tahlee Stone and Allen Zhang, and the support from many Blood Service personnel including Perfecto Diaz, David Irving, Geoff Smith and Dan Waller who have generously given their time and energy with institutional details, guidance and service. We would like to acknowledge the Australian Red Cross Blood Service and Australian governments that fully fund the Blood Service for the provision of blood products and services to the Australian community.
} 


\section{Introduction}

Philanthropy and volunteerism play a major role in most countries (List 2011). ${ }^{1}$ Understanding what factors influence individuals to donate and volunteer has thus received a great deal of attention, including increasing interest in gender differences in altruism. Croson and Gneezy's (2009) review of this literature finds mixed evidence regarding which gender is more altruistic, suggesting a more nuanced understanding of gender differences in altruism is needed. Working in this direction, DellaVigna et al. (2013) examine "the overall distribution in social preferences and, in particular, marginality." 2 They find that women are more responsive to treatment effects, suggesting that marginal donors (people who are close to indifferent between donating and not donating) are disproportionately female. Their evidence is consistent with the argument made by Croson and Gneezy (2009) that women are more sensitive (or closer to the margin) and thus more responsive to social cues. ${ }^{3}$ These results are interpreted as implying that the height of the latent altruism distribution is greater for women than men at the margin of willingness to donate.

In our paper, we sketch a model of donation behaviour assuming that the distribution of latent altruism is narrower and more peaked for women than men, and consider donation activity that is concentrated among donors in the right tail of the altruism distribution. Given simple conditions, we show that a greater overall proportional change in donations by women than men occurs in response to a shock to latent altruism. We then theoretically examine the implications for subgroups of the population that are ranked ex ante in terms of first order stochastic dominance of their respective latent altruism distributions. We conjecture (assuming reasonable conditions) that the additional responsiveness of females to shocks is greater among donor subgroups with lower altruism levels. In other words, the lower the ex ante likelihood that a subgroup of people will donate, the greater the additional proportional effect on donations a positive shock to latent altruism will have on women than men.

To test the theoretically implied gender differences in altruism, we examine the effect of the 2009 Victorian Bushfires natural disaster, a natural experiment, on blood product

\footnotetext{
${ }^{1}$ E.g., the estimated annual market value of volunteering activities in the US is $\$ 175$ billion (Wareld, 2013).

${ }^{2}$ DellaVigna et al. use the economic terminology meaning of marginal; to identify individuals who are (close to) indifferent between donating and not donating. In this paper, we give marginality the same meaning.

3 Andreoni and Vesterlund (2001) find that men are more responsive than women to price in a laboratory dictator game. However, their aggregate result is driven by greater inequality aversion amongst females. This evidence seems less relevant in blood donation and other contexts where there is no natural reference point for equality or fairness.
} 
donations in Australia. ${ }^{4}$ Controlling for seasonal variation and annual trends in donations using a difference in differences approach, we test whether there is an overall gender difference in the response of donors to the Bushfires. Further, we ex ante categorise donors into subgroups with different, and narrower, distributions of latent propensity to donate blood, using several measures of past donation intensity as proxies for unobservable latent altruism. As these exogenously defined subgroups have differing densities of individuals on the donation margin, this allows us to examine gender differences at multiple margins on the altruism distribution.

Our results go beyond being consistent with DellaVigna et al.'s conclusion regarding gender differences in the distribution of social preferences. First, we find that women are significantly more responsive than men to the Bushfires in donating blood products, consistent with DellaVigna et al.'s conclusion, but in a vastly different context ${ }^{5}$ with a dramatically larger sample. ${ }^{6}$ We also show, as conjectured, that the gender gap is largest among the ex ante defined least altruistic donor subgroups and diminishes the more altruistic the donor subgroups are. This latter result is novel in the literature and implies that gender differences in altruism depend on the characteristics of the population considered, and in particular the position of donors in the distribution of altruism.

Our results, in combination with DellaVigna et al., suggest that the greater overall marginal effect among women than men is not isolated to some specific psychological gender response to either costs or benefits alone, but a rational weighing of costs and benefits. In either study alone, one could question whether women are merely more responsive (experiencing a larger mean shift in altruism) to the specific phenomenon being considered, such as turning down a request to help, avoiding a face-to-face solicitation, a shift in costs, a shift in benefits, or a natural disaster. ${ }^{7}$ Combining the evidence, the more diverse dimensions

\footnotetext{
${ }^{4}$ Although not their focus, regressions in Eckel et al. (2013) from an experiment on giving to organizations supporting victims of Hurricane Katrina indicate that female participants gave more money than male participants.

${ }_{5}^{5}$ DellaVigna et al. (2013) provide evidence from a door-to-door field experiment solicitation of monetary donations. By comparison, our paper considers a unique population, a natural experiment, a distinct opportunity for helping others, and a random shock that shifts benefits rather than costs.

${ }^{6}$ Figure 1 in DellaVigna et al. (2013) implies that the total number of successful solicitations in their opt-out treatment is approximately 30 subjects. By comparison, we observe over 120,000 donation attempts during the post-bushfire treatment period.

${ }^{7}$ In a deterministic model, females being more responsive in general to shocks of a given magnitude because their latent preferences have a narrower distribution is analogous to having identical preference distributions across genders but different proportional shifts in latent altruism by gender. A larger mean shift for females than males yields very similar testable hypotheses, making strict differentiation in a single context difficult. Further, the intuition is similar in either case; if women are more affected by shocks in general, they are essentially more marginal.
} 
in which women are more responsive, the more confident we can be that women are more responsive in general. ${ }^{8}$

Our paper is organized as follows. Section 2 sketches a theoretical model that predicts different behavioural responses in the presence of gender heterogeneity in the distribution of latent altruism. Section 3 describes the natural disaster, the Australian blood donation context, the data and our empirical strategy. Section 4 presents the results and Section 5 concludes.

\section{Model}

This section presents a reduced form model of donation behaviour by gender, assuming a narrower and more peaked distribution of latent altruism for women than men. In particular, it considers the implications for changes in donation intensity following a common altruism shock to the donation preferences of all potential donors. We first present a deterministic model that provides basic intuition and captures the core concepts of DellaVigna et al.'s framework with a more peaked distribution for women than men, and then a stochastic model that includes more realistic assumptions.

\subsection{Deterministic Model of Donation Behaviour}

Consider distributions of the latent propensity to donate blood for males and females as shown in Figure 1, where $f(l)$ and $m(l)$ are the probability density functions of females and males, respectively, at latent propensity $l$, and $F(l)$ and $M(l)$ are the respective cumulative densities. To begin, assume a simple deterministic world where all individuals with net benefit (utility from donating less time and effort costs) greater than zero donate. With a population of $N_{M}$ men and $N_{F}$ women, there are $(1-M(0)) * N_{M}$ male and $(1-F(0)) * N_{F}$ female donation attempts.

Suppose an event (such as a natural disaster) occurs, temporarily increasing the utility for donating by $\mu$ for all individuals. ${ }^{9}$ This shifts the entire willingness distribution to the right, analogous to shifting the threshold for donating leftwards by $\mu$, such that all individuals with latent utility originally greater than $-\mu$ then make donation attempts. Figure 1 shows the increase in the number of donors (as a proportion of the relevant population) is governed by

\footnotetext{
${ }^{8}$ In both our study and DellaVigna et al's study, donations are on the right tail of the distribution, where the theory predicts women will be more responsive in aggregate.

${ }^{9}$ Psychologists studying the effects of disasters on altruism find the effects short lived, supporting our assumption of a short-term shock. For instance, Li et al. (2013) find that children gave more in dictator games immediately after than before experiencing a natural disaster, but reverted to giving the same pre-disaster amounts three years later.
} 
$\int_{-\mu}^{0} m(l) d l<\int_{-\mu}^{0} f(l) d l$, for which a sufficient condition is that the interval $(-\mu, 0]$ lies wholly within the region where the density of female donation propensity is greater than the equivalent density for males, which captures the key assumption that females have a narrower and more peaked distribution. For $N_{F} \approx N_{M}$, this predicts a larger absolute increase in the number of female than male donors. Similarly, if $F(0) \approx M(0)$ such that roughly equal numbers of males and females are donors, this predicts a larger proportional increase in the number of female donors in response to positive exogenous shocks.

Figure 1: Distributions of latent altruism by gender

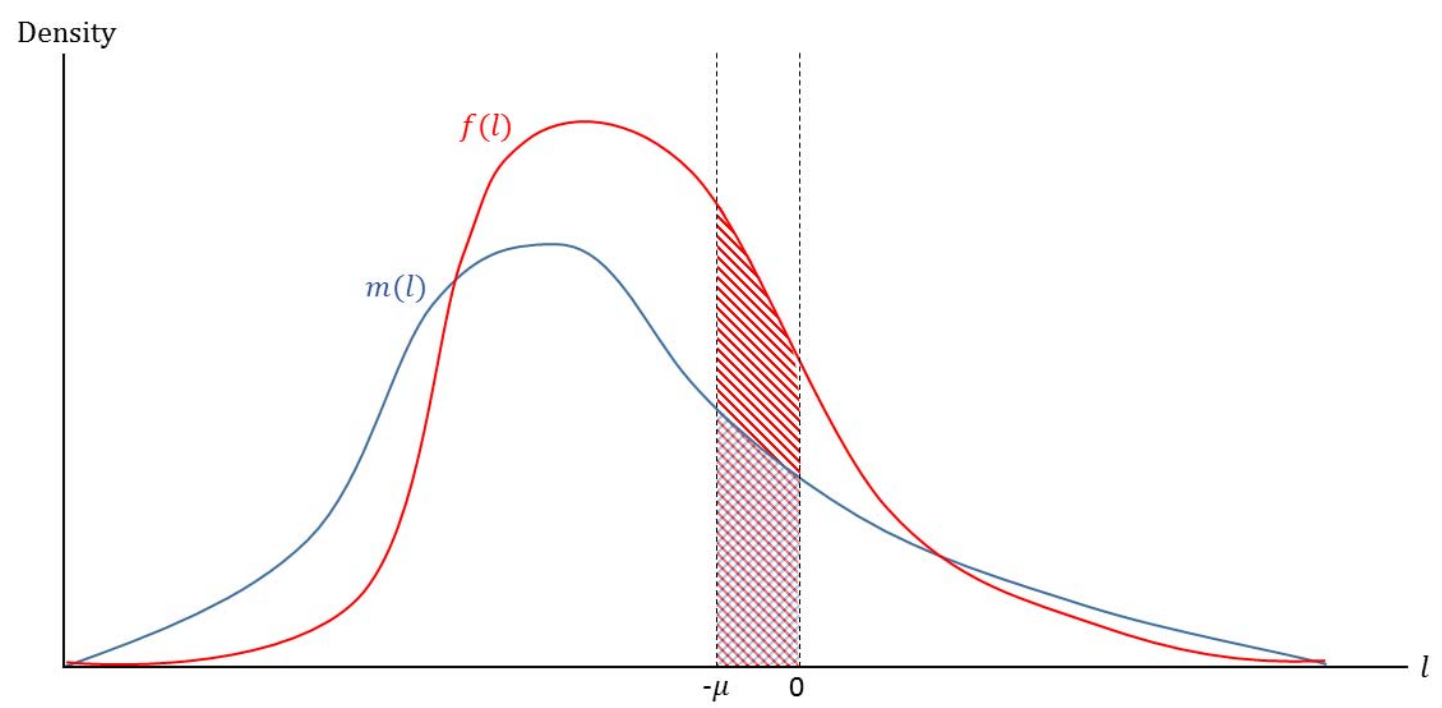

\subsection{Stochastic Model of Donation Behaviour}

Now consider heterogeneity in the effect of a positive altruism shock for groups of individuals categorised ex ante by their latent donation propensity. Figure 2 shows the overall latent altruism distribution and identifies three distinct sub-groups, denoted $\mathrm{A}, \mathrm{B}$ and $\mathrm{C}$, that are defined by their latent altruism. ${ }^{10}$ For example, subgroup A may contain donors with only one donation that occurred over a year ago, while subgroup $\mathrm{C}$ could contain donors with several donations within the past year. Here, intuition requires allowing that donations are not entirely deterministic, ${ }^{11}$ but determined by an individual's latent donation propensity plus an independent random draw at time $t, \varepsilon_{i t}$, that captures idiosyncratic shocks (such as variation in the opportunity cost of time or health shocks). Accordingly, individuals donate at time $t$ if

\footnotetext{
${ }^{10}$ The scale of the overall distribution is retained so that the densities sum across groups to give the overall pdfs for each gender.

${ }^{11}$ In a deterministic framework, neither high nor low propensity types would exhibit behavioural change in response to a positive shock, with associated individuals respectively always or never donating in both the baseline and positive shock scenarios.
} 
donation utility, $l_{i}+\varepsilon_{i t}$, is greater than zero, which yields a donation probability $1-\Omega(-l)$, where $\omega(\cdot)$ and $\Omega(\cdot)$ are the pdf and cdf of $\varepsilon$, respectively.

This non-deterministic framework yields several intuitive and useful implications. First, the proportional increase in donation probability caused by a marginal change in $l$ equals the hazard rate $\omega(-l) /(1-\Omega(-l))$ of $\varepsilon$. Thus, the total proportional effect of a discrete change of magnitude $\mu$ in latent altruism $l$ is

$$
\Delta(l):=\exp \left(\int_{l_{i}}^{l_{i}+\mu} \frac{\omega(-x)}{1-\Omega(-x)} d x\right)-1 .
$$

Assuming that the distribution of the idiosyncratic error term $\varepsilon_{i t}$ has an increasing hazard rate, the proportional increase in donation probability is falling in $l$, irrespective of the distribution of $l .{ }^{12}$ Aggregating over donors with common $l$, if the proportional increase in the donation probability is falling in $l$, then within each gender the proportional increase in the number of donation attempts induced by a positive shock is greater among less altruistic (lower l) donors. Further, since the hazard rate is weakly positive by definition, the proportional effect on donations is positive everywhere on the distribution and increases in the magnitude of the shock $\mu$.

Figure 2: Heterogeneous density of latent altruism

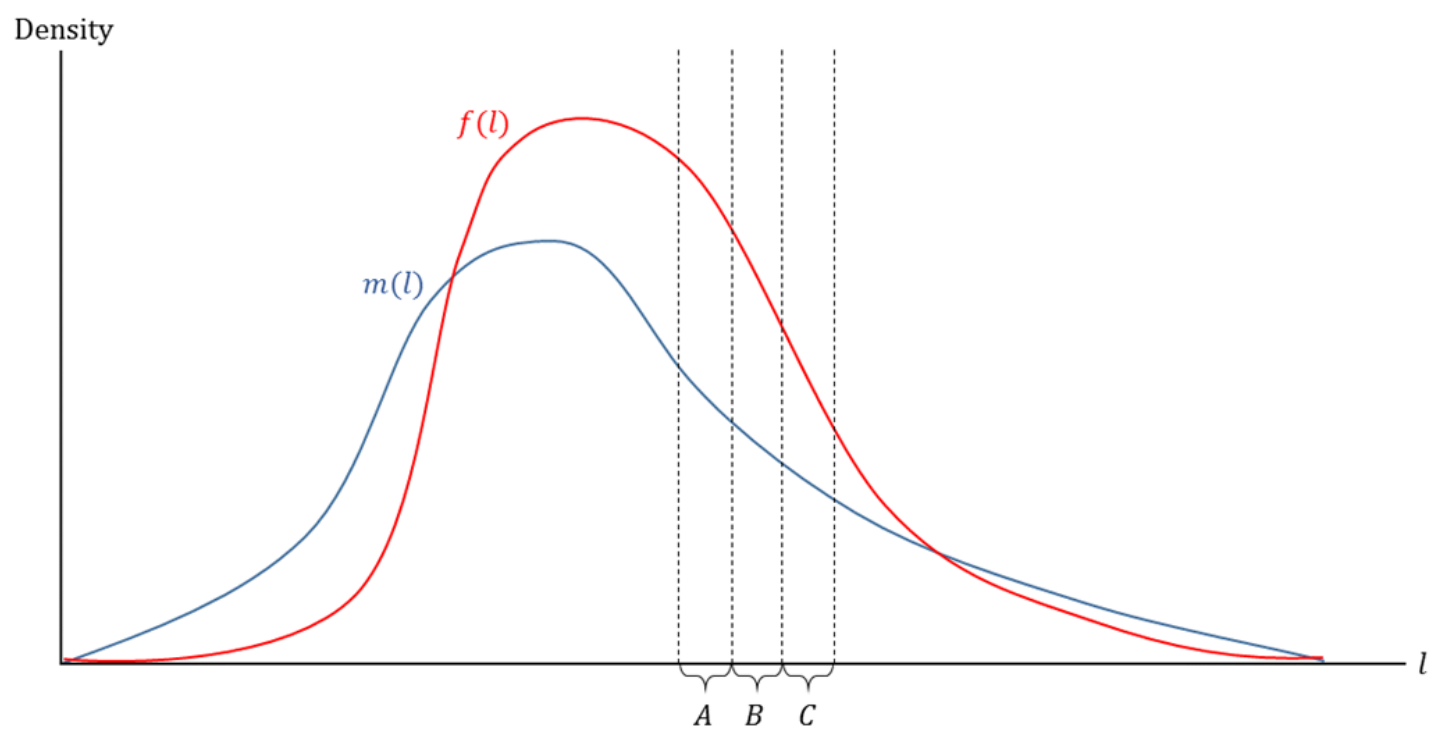

\footnotetext{
${ }^{12}$ Increasing hazard of $\varepsilon_{i t}$ is not an overly restrictive requirement; indeed the normal and logistic error terms commonly used in discrete choice models have this property. The assumption is made in the current context to capture the intuition that the proportional effect of a positive shock on donations will plausibly be largest for donors with the lowest ex ante donation probability. Ultimately, this assumption is strongly supported by the results shown in Section 4.
} 
Now consider the aggregate proportional increase for ex ante determined groups of donors, defined by ranges of $l$, for example $\left[l_{0}, l_{1}\right]$. This is the population and prior donation probability weighted average of individual proportional increases. For females and males respectively, the proportional changes are

$$
\Delta_{G}^{f}:=\frac{\int_{l_{0}}^{l_{1}} \Delta(l) * f(l) *(1-\Omega(-l)) d l}{\int_{l_{0}}^{l_{1}} f(l) *(1-\Omega(-l)) d l} \text { and } \Delta_{G}^{m}:=\frac{\int_{l_{0}}^{l_{1}} \Delta(l) * m(l) *(1-\Omega(-l)) d l}{\int_{l_{0}}^{l_{1}} m(l) *(1-\Omega(-l)) d l} .
$$

As $\Delta(l)$ is decreasing in $l$, it immediately follows that for each gender, the proportional effect of the shock on donations is greater in groups characterised by lower altruism levels. Further, a natural implication of the assumption of a narrower, more peaked, distribution of altruism in women compared to men is that $f(l) / m(l)$ is decreasing in $l$ for much of the right tail of $l$ (see Figure 2). Given that $\Delta(l)$ is decreasing in $l$, and assuming $f(l) / m(l)$ is decreasing on the interval $\left[l_{0}, l_{1}\right]$ covered by an arbitrary grouping, then within the group the male distribution of altruism $m_{G}(l)$ stochastically dominates the female distribution $f_{G}(l)$, such that $\Delta_{G}^{f}>\Delta_{G}^{m}$, since $f(l) *(1-\Omega(-l))$ places a higher weight on low $l$ individuals with higher proportional changes in donations. In other words, combining (a) the decreasing proportional response of donors to shocks as $l$ increases with (b) the decreasing relative prevalence of female donors to male donors over the entire interval of values of $l$ covered by a group, also as $l$ increases, the additional female response will be positive.

For donors on the right tail of the altruism distribution (where blood donors are likely concentrated, since less than 10 percent of individuals donate in any country, Slonim et al., 2014), the model predicts proportional changes in donations to be larger among lower altruism donor groups, and larger for females than males within a group. However, without imposing arbitrary additional restrictions on the shape of $\Delta(l)$ and $f(l) / m(l)$, the model gives no exact prediction of how the additional female response should vary in $l{ }^{13}$ Yet, if the changes in $\Delta(l)$ and $f(l) / m(l)$ are relatively balanced across groups, the difference in weightings between genders will be similar in all groups. Then for groups characterised by lower altruism, similar weighting differences applied to larger proportional $\Delta(l)$ effects will yield larger absolute differences in proportional effects. ${ }^{14}$ Hence, we conjecture that excess

\footnotetext{
${ }^{13}$ Consider two groups, which cover altruism levels $\left[l_{0}, l_{1}\right]$ and $\left[l_{1}, l_{2}\right]$ respectively, for $l_{0}<l_{1}<l_{2}$. The excess female response will tend to be higher for the first group if $\Delta(l)$ and/or $f(l) / m(l)$ are falling rapidly between $l_{0}$ and $l_{1}$, but relatively flat between $l_{1}$ and $l_{2}$.

${ }^{14}$ For example, multiplying $\Delta(l)$ by a positive constant $k$ for both genders increases the absolute difference between $\Delta_{G}^{f}$ and $\Delta_{G}^{m}$, from $\Delta_{G}^{f}-\Delta_{G}^{m}$ to $k\left(\Delta_{G}^{f}-\Delta_{G}^{m}\right)$.
} 
female proportional changes that fall in $l$ are a sensible, albeit not guaranteed, prediction implied by the model that assumes a narrower and more peaked distribution of latent altruism for women than men.

For this theoretical conjecture to hold, it is not necessary for donor groups to be sharply defined by precise minimum and maximum latent altruism levels. This is important since in practice as $l$ is unobserved, donor groups can only be defined based on historical donor behaviour, which clearly does not sort donors perfectly by $l .{ }^{15}$ However, provided that the distribution of latent altruism in groups demonstrating more altruistic prior behaviour stochastically dominates that of groups demonstrating less altruistic prior behaviour, then both the results of greater proportional response for both genders, and the conjecture of greater additional female response, in lower quality groups, transfer to the more general setting. ${ }^{16}$

An important qualifier is that gender differences in mean altruism could yield either excess male or female responses to shocks, depending on the shape of $m(l) / f(l)$, and thus could offer a confounding explanation. However, in the full dataset, females constitute $55 \%$ of all donors and make $52 \%$ of donations, suggesting any mean altruism difference is minimal (see Online Appendix A4 for further details).

\section{Background}

\subsection{The Victorian Bushfires ${ }^{17}$}

The Victorian Bushfires primarily began on February 7, 2009, and were a high-profile natural disaster. ${ }^{18}$ Over 400 distinct fires broke out across six regions of Victoria (the most densely populated Australian state) during extreme fire weather conditions that consisted of record high temperatures (over 110 degrees), extremely low humidity (under six percent), and high winds (over 60 miles per hour). The Bushfires remained out of control for several days and were finally controlled and considered no longer a threat in early March. The Bushfires were

\footnotetext{
${ }^{15}$ For example, under the model, individual $i$ may have more intense donation history than individual $j$ yet $l_{i}<l_{j}$ if $i$ has, by chance, received sufficiently large and positive stochastic draws.

${ }^{16}$ Consider two groups: $L$ and $H$. Each now can have density at a common arbitrary $l$ for each gender. By definition of the random (past) shocks being i.i.d, $f_{G}(l) / m_{G}(l)$ is identical across groups (at $l$, some share of both males and females received shocks sufficient to induce stated behaviour). Under the model, the probability of being in a higher group of past behaviour is increasing in $l$, yielding the required between group stochastic dominance result.

17 Information presented in this section comes from http://en.wikipedia.org/wiki/Black_Saturday_bushfires (last accessed August 3, 2015). More details and references can be found there.

${ }^{18}$ The Emergency Events Database (http://www.emdat.be/) categorizes an event as a disaster if at least one of the following criteria is met: (1) 10 or more people are reported killed, (2) at least 100 people are affected, (3) a state of emergency is declared, or (4) a call for international assistance is issued. All criteria were met within the first few days of the Bushfires.
} 
the most damaging fires in Australia's post-European history and estimated to be the eighth worst globally in modern history. They resulted in 100 male and 73 female lives lost (though during the first few weeks the estimated loss of life was substantially higher), 414 injuries, 1.1 million acres burned entirely, over 2,000 houses entirely destroyed, 7,500 people displaced, and involved more than 3,500 firefighters.

It is hard to imagine that anyone in Australia was unaware of the disaster. The fires were reported on every major print, TV and online source with extended coverage starting February $7^{\text {th }}$ and continuing throughout the month. By mid-February, Australians nationwide flew flags at half-mast and wore yellow ribbons to commemorate the victims. Major aid organizations received over $\$ 372$ million in monetary donations.

The Australian Red Cross Blood Service (the Blood Service), however, neither attempted nor needed to increase its solicitation of donors. First, of the 414 injuries, only 22 were major burn victims that needed triage, and hence the need for extra blood was minimal. Second, given the short time that whole blood can be maintained (42 days, with hospitals preferring blood donated within 7 days), a request for more blood could be potentially wasteful in the absence of extra immediate need. Third, seasonal variation in whole blood demand and supply usually result in surpluses during the summer (when the Bushfires occurred) and shortages during the winter, for which whole blood collected during the Bushfires would not have been able to be stored. Thus, observed increases in donations cannot be attributed to changes in Blood Service policies, which is important since otherwise a change in policy could potentially have had (intentional or inadvertent) heterogeneous gender effects.

\subsection{The Australian Red Cross Blood Service}

Studying blood donations in Australia (see discussions in Slonim et. al. (2014) and Garbarino et. al. (2013)) is advantageous since all blood products are collected by a single organization, the Blood Service. Having a single collection entity means that all donation attempts can be observed and ensures homogenous collection procedures and communications. Further, compared to less differentiated and more fungible donations, the results are unlikely to be affected by substitution between donation type that differed by gender post-bushfire. ${ }^{19}$

\footnotetext{
${ }^{19}$ For example, if males substituted to labour-intensive donations while women donated blood post-Bushfires, this would falsely yield a result of female excess sensitivity. This would imply smaller gender differences in states other than Victoria, where such substitution is less feasible due to geographic distance. However no such distinction is found, with similar gender differences found in Victoria, states close to Victoria, and the Australian states and territories furthest away from Victoria (results omitted, see Online Appendix A2).
} 
The dominant blood products donated in Australia are whole blood and plasma. Donors are eligible to donate whole blood once every 12 weeks and plasma once every two weeks, and can donate plasma four weeks after a whole blood donation and whole blood two weeks after a plasma donation. The Blood Service also requires all first time donors to donate whole blood at least one time before they can attempt to donate plasma. ${ }^{20}$

\subsection{Data}

The dataset used is the universe of recorded individual blood donation attempts made through the Blood Service (i.e., anywhere in Australia), primarily beginning in 2001 and continuing through the end of $2013 .^{21}$ The sample used in the analysis is restricted to donors with a fullyknown donation history ${ }^{22}$ and excludes donors who make therapeutic donations. ${ }^{23}$ To isolate the causal effect of the Bushfires on donation activity, the analysis focuses on donations made during equivalent 12-week periods in 2008, 2009 and 2010 that extend from four weeks before to eight weeks after February 7 in each year. This yields a sample containing a total of 460,478 blood product donation attempts collectively made by 317,786 individuals. $^{24}$

Each donation attempt observation contains the unique identification number (ID) of the donor, the date the attempt was made, the outcome of the attempt (that is, the blood product donated, for example whole blood or plasma, or the unsuccessful attempt reason), donor gender and the location of the donor's first donation attempt. The ID allows each donor's full donation history to be identified. For each attempt in the 36-week sample period, this information is used to construct several measures of the donor's prior donation behaviour from their entire prior attempt history.

\footnotetext{
${ }^{20}$ Note that the eligibility rules limit how often an individual can donate within a specified time period (e.g., at most one whole blood donation within 12 weeks of the Bushfire), and thus are more likely to constrain increases in donation intensity by the most committed donors in response to the Bushfire. A natural concern is that this may produce different bushfire effects across groups by construction. However, since the theory concerns the distribution of donor preferences and makes predictions about changes in the number of individuals who donate (rather than number of donations specifically), the time requirement between donations is advantageous for our methodology by preventing distortions by individuals making many donations each. The analysis could instead count only the number of unique donors in a period. However, this would require making arbitrary distinctions about the length and date cutoffs of a period, which could then distort the results.

${ }^{21}$ We examine attempts since we are interested in donor intention regardless of whether they are successful. An attempt involves checking into a donation centre and completing the initial paper work to donate.

${ }^{22}$ The prior donation history of some donors, in particular many who made their first attempt prior to 2001, appears to have been lost. Hence these donors and all attempts they have made are excluded from the analysis. Conversely, a small number of donors who made their first attempt prior to 2001 have full donation records, and are thus retained in the sample.

${ }^{23}$ Therapeutic donations indicate a donor has medical reasons for donating blood, and thus these donors are largely irrelevant when considering prosocial intentions. A small number of duplicate observations and observations with missing information about gender or the blood product donated are also removed.

${ }^{24}$ The exclusion of therapeutic and partial history donors reduces the sample size by roughly one-quarter. Were these donors retained, the sample would include 599,060 donation attempts made by 375,030 donors.
} 
Table 1 provides a snapshot of the donors in the population. Columns 1-3 show statistics for any donor with at least one donation attempt in the 36-week sample period and Columns 4-6 show the same information for anyone who made at least one attempt during the eight weeks following the bushfire. Over all 36 weeks, women were 56 percent of donors and made 54 percent of all donation attempts, with higher shares following the Bushfires. The vast majority of donors provided either whole blood or an apheresis donation (plasma or platelets), constituting over 90 percent of all attempts. The Bushfires also attracted donors with less history; over all 36 weeks, donors had made on average 4.93 donation attempts in the past, while during the 8 weeks immediately after the Bushfires the average donor had made only 4.20 prior attempts. A disproportionately large percent of new donors and longlapsed donors (those who had not donated in at least two years) attempted to donate following the Bushfires; although the Bushfire period represents only 2/9 (8/36) of the sample period, it accounts for over $1 / 3$ of the new donors and long-lapsed donors.

Table 1: Summary of Donation Attempts during the 36 Week Analysis Period

\begin{tabular}{|c|c|c|c|c|c|c|}
\hline & \multicolumn{3}{|c|}{ All 36 Weeks } & \multicolumn{3}{|c|}{$\begin{array}{c}8 \text { Week Bushfire Period } \\
\text { (Feb 7-Apr 3, 2009) }\end{array}$} \\
\hline & All & Female & Male & All & Female & Male \\
\hline Donation Attempts & 460,478 & 248,832 & 211,646 & 121,496 & 68,256 & 53,240 \\
\hline Female $(\%)$ & $54.0 \%$ & & & $56.2 \%$ & & \\
\hline Donors & 317,786 & 178,085 & 139,701 & 115,360 & 65,644 & 49,716 \\
\hline Female $(\%)$ & $56.0 \%$ & & & $56.9 \%$ & & \\
\hline Whole Blood Donations & 374,439 & 203,009 & 171,430 & 100,668 & 56,733 & 43,935 \\
\hline Apheresis Donations & 48,864 & 19,733 & 29,131 & 10,831 & 4,362 & 6,469 \\
\hline Unsuccessful Attempts & 37,175 & 26,090 & 11,085 & 9,997 & 7,161 & 2,836 \\
\hline \multicolumn{7}{|l|}{ Lifetime Prior Attempts } \\
\hline Mean Total Donations & 4.93 & 4.37 & 5.60 & 4.20 & 3.66 & 4.88 \\
\hline 0 Attempts (First Donation) & 96,378 & 54,377 & 42,001 & 36,222 & 21,615 & 14,607 \\
\hline 1 Attempt (First Return) & 65,578 & 37,272 & 28,306 & 17,098 & 9,882 & 7,216 \\
\hline 2 Attempts & 51,804 & 29,607 & 22,197 & 12,541 & 7,360 & 5,181 \\
\hline 3-4 Attempts & 76,004 & 43,068 & 32,936 & 17,140 & 9,949 & 7,191 \\
\hline 5-9 Attempts & 97,139 & 51,877 & 45,262 & 22,078 & 12,060 & 10,018 \\
\hline $10+$ Attempts & 73,575 & 32,631 & 40,944 & 16,417 & 7,390 & 9,027 \\
\hline $\begin{array}{l}\text { Long-Lapsed Donation } \\
\text { ( } 0 \text { attempts in past two years })\end{array}$ & 16,782 & 10,486 & 6,296 & 5,869 & 3,825 & 2,044 \\
\hline Attempts in Past Year ${ }^{\mathrm{a}}$ & 2.72 & 2.31 & 3.19 & 2.62 & 2.17 & 3.16 \\
\hline
\end{tabular}

\subsection{Empirical Strategy}

This paper presents results comparing the number of attempts after the bushfire to the number of attempts during the control periods. February 7, 2009, being both the start date of the 
Victorian Bushfires and the day on which peak destruction occurred, provides a natural point for additional donor responses to begin. However, since the salience of a natural disaster presumably attenuates over time, there is no obvious end date for when any additional donations may have occurred. To capture potential variation in donor responses over time, the Bushfire period is separated into three date windows of one, two to four, and five to eight weeks from the onset of the Bushfires, with results presented for each of these windows.

To measure the causal effect of the Bushfires on donation behaviour, we estimate a difference in differences effect to control for time-and-bushfire invariant differences between genders, ${ }^{25}$ seasonal effects and time trends. To capture time trends, we use donation attempts in 2008 and 2010 as a joint control. The difference in differences analysis is thus analogous to calculating the change in the number of donations in the date windows after the Bushfires relative to a pre-disaster period (defined as the four weeks immediately preceding the Bushfires), and subtracting from this the (placebo) change in donations observed at the identical time of the year exactly one year before and one year after to control for seasonal patterns in donations.

Within 2009, donation attempts that occurred in the four weeks immediately preceding the Bushfires set a base level against which the change in donation attempt rates post-bushfire is measured. This four week time period is sufficiently long to provide a large amount of data yet avoids the New Year's holiday period. In all, we analyse 36 weeks of data (four weeks before February 7 to eight weeks after) over three years (2008 to 2010), with controls for both seasonality (date window dummies) and time trends (year dummies). While February 7 falls on a different day of the week in each year, utilising full week periods in the analysis ensures that the day of week composition of the sample period is balanced. ${ }^{26}$ We further include dummy variables for day of week to capture within-week variation and thus improve estimation precision. For the same reason, a public holiday dummy is added to capture the very low number of donation attempts made on days such as Easter Friday, Easter Sunday and Australia Day, when most or all donation centres are closed.

Our unit of observation is the total number of donation attempts made on each date $t$ in the sample for donors of a given observed type $G$ (discussed below), separately by gender $g$.

\footnotetext{
${ }^{25}$ For example the opportunity cost of time, or attitudes towards blood donation, may differ by gender, but if these factors are not altered by the bushfire, they will be netted out by the difference in differences strategy.

${ }^{26}$ The sample period begins January 10 and ends April 3 in each year, except 2008 when the end date is April 2 due to the leap day. The starting day of the week thus varies; the sample period runs from a Thursday to a Wednesday in 2008, from a Saturday to a Friday in 2009, and from a Sunday to a Saturday in 2010.
} 
To be consistent with the theoretical prediction of proportional responses, the natural logarithm $\ln \left(\right.$ attempts $\left._{g G t}+1\right)$ is used as the dependent variable in most regressions, with the unitary offset used to avert undefined values stemming from the existence of dates in the sample period (in particular some public holidays) where donor groups do not have any donation attempts. The effect of the Bushfires is captured by interactions of the date windows with the post-bushfire period in 2009. To investigate the possibility of differential response by gender, a third dimension of differencing is introduced by interacting each of the controls (dummy variables for year, date window, day of week, and public holiday) and the interaction of date windows with the post-bushfire period in 2009, with gender. Accordingly, the model used for estimation has the following specification:

$$
\begin{aligned}
y_{g, t}=a+\beta_{f} * \text { Fem }+ & \sum_{y=2009}^{2010} \beta_{y} * D_{y}+\sum_{w=1,2-4,5-8} \beta_{w} * D_{w}+\sum_{y=2009}^{2010} \beta_{y}^{f} * \text { Fem } * D_{y}+\sum_{w=1,2-4,5-8} \beta_{w}^{f} * F e m * D_{w} \\
& +\sum_{y=09} \sum_{w=1,2-4,5-8} \beta_{b, w} * D_{y} * D_{w}+\sum_{y=09} \sum_{w=1,2-4,5-8} \beta_{b, w}^{f} * F e m * D_{y} * D_{w} \\
& +\sum_{d=\text { Tues }}^{\text {Sun }} \beta_{d} * D_{d}+\sum_{d=\text { Tues }}^{\text {Sun }} \beta_{d}^{f} * \text { Fem } * D_{d}+\beta_{p} * D_{p}+\beta_{p}^{f} * \text { Fem } * D_{p}+\varepsilon_{g, t}
\end{aligned}
$$

where $D_{y}, D_{w}, D_{d}$, and $D_{p}$ are dummy variables for the year, date window (within 1, 2-4, and 5-8 weeks post bushfire), day of the week, and public holiday status, respectively. Coefficient estimates for these controls are, respectively, $\beta_{y}, \beta_{w}, \beta_{d}$ and $\beta_{p}$, while the additional marginal female effect for each is given by $\beta_{x}^{f}$. The omitted categories are the year 2008 , the date window of the four weeks prior to the February 7 date of the bushfire, and Monday for day of week. Primary interest is given to the coefficients for the marginal effect of the post-bushfire date windows in 2009, denoted $\beta_{b, w}$ and $\beta_{b, w}^{f}$ for the main effect and additional female effect, respectively. $\beta_{b, w}$ is thus the estimated bushfire effect for males, $\beta_{b, w}^{f}$ is the additional (marginal) effect for females, and $\beta_{b, w}+\beta_{b, w}^{f}$ is the total female effect. In the logarithmic specifications, these are proportional increases of approximately $\exp \left(\beta_{\mathrm{b}, \mathrm{w}}\right)-1$, $\exp \left(\beta_{b, w}^{f}\right)-1$ and $\exp \left(\beta_{b, w}+\beta_{b, w}^{f}\right)-1$.

We estimate OLS models and cluster robust standard errors on the date of attendance to account for unobserved (daily) shocks that affect both male and female donation rates contemporaneously. Models which include weekends (only weekdays) in the sample have 252 (180) days of observations (12 weeks times 3 years times 7 (5) days) for each gender, giving 504 (360) observations in 252 (180) clusters in total. The tables presenting the results 
show the core parameter estimates of $\beta_{b, w}$ that capture the male difference in differences response during 2009 for 1, 2-4 and 5-8 weeks after the fires, and $\beta_{b, w}^{f}$ that capture the additional female difference in differences response for the same periods.

\section{4. $\quad \underline{\text { Results }}$}

\subsection{Descriptive Results}

Figure 3 shows the average number of donation attempts per week for all men and women, for the date windows that cover the period 4 weeks prior to 8 weeks past February 7 , separately for the control years $(2008,2010)$ and treatment year (2009). For both genders, there is little discernible change in attempts around the Bushfire date in the placebo years (2008, 2010), but a sizable increase immediately after the Bushfires in 2009 which diminishes over the following eight weeks. Consistent with DellaVigna et al. (2013), the increase is noticeably larger for women than men in both absolute and proportional terms; women appear more responsive to the disaster.

Figure 3: Weekly Donation Attempts by Gender and Bushfire Year

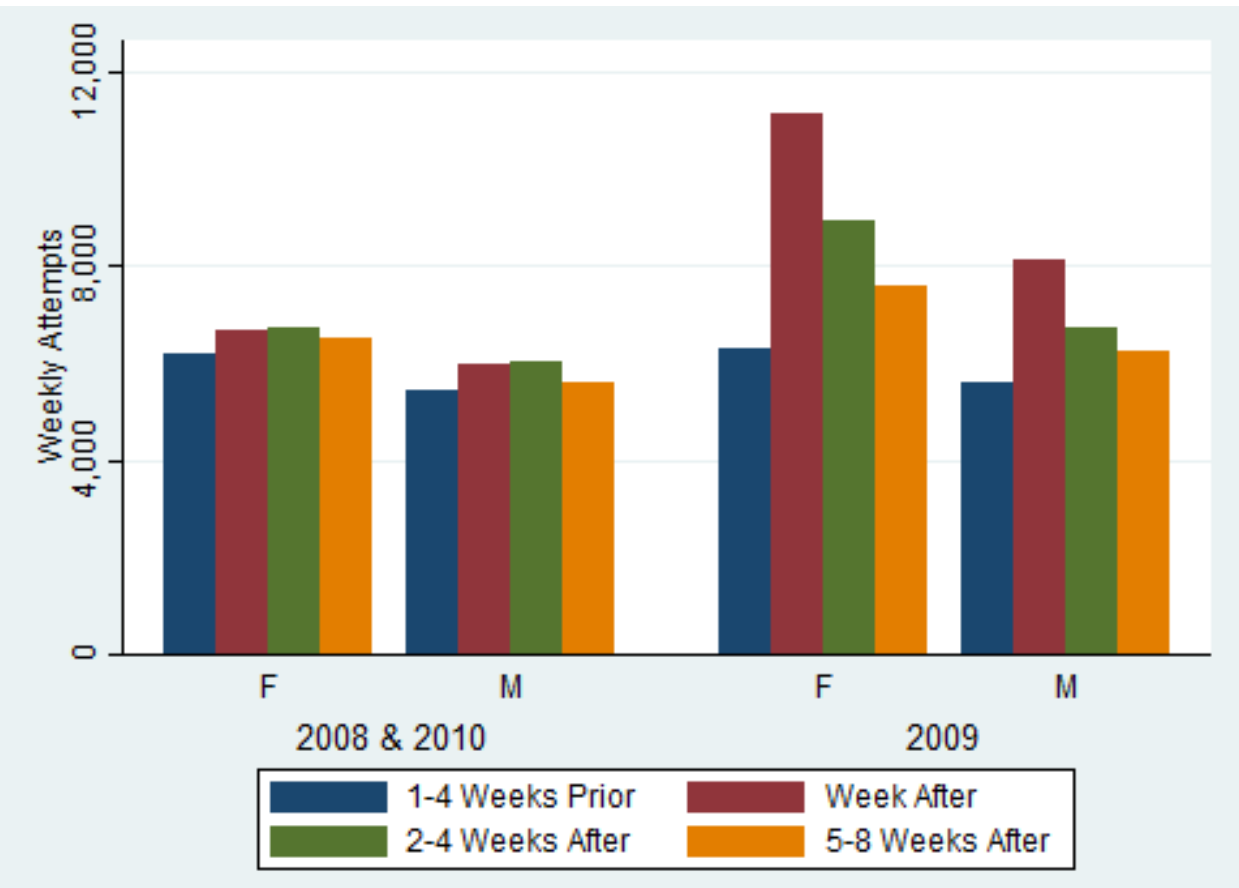

As there is minimal seasonality over the 12 weeks in the control years, Figure 4 shows the number of weekly attempts in 2009 only, disaggregating the data by one measure of prior donation behaviour that may reflect differences in latent altruism; the length of time since the donor's prior attempt. For clarity, the groups of donors shown in Figure 4, new donors and donors with their most recent donation attempt occurring in the previous 3-6 months, are at opposite ends of the donation intensity spectrum. Among male and female new donors, a 
similar pattern to the overall responses in Figure 3 is evident; donation attempts increase immediately after the Bushfires, and the effect is substantially larger for women than men. In contrast, donors with a most recent attempt in the prior 3-6 months (that is, active recent donors), exhibit a much weaker response to the disaster, and no gender difference is apparent.

Figure 4: Weekly Donation Attempts in 2009 by Gender and Time Since Prior Attempt

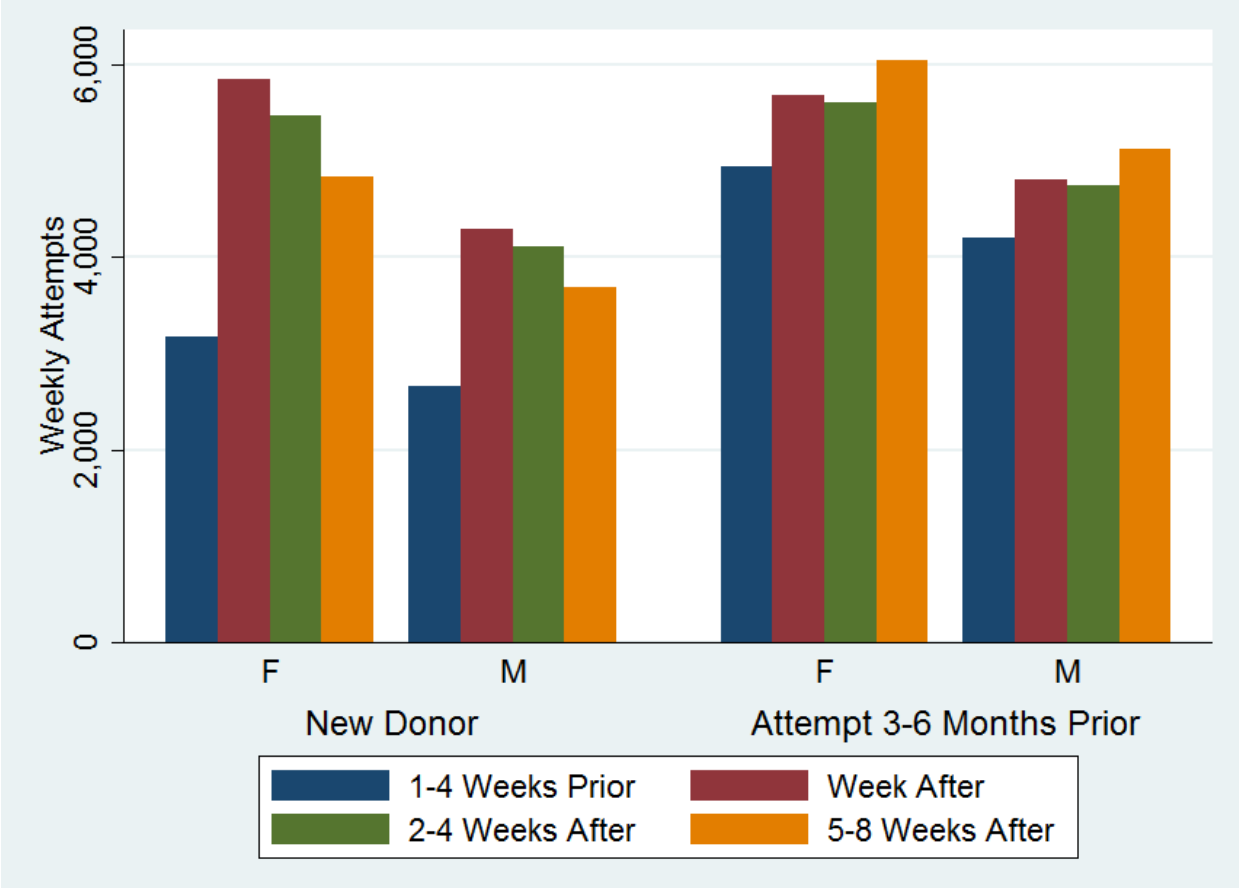

\subsection{Model Estimates: Overall Results}

Tables 2-5 present the core estimates of the model specifications in Section 3.4. Table 2 presents the results using all donation attempts, separately by gender. Columns 1-3 show estimates from linear models and Columns 4-6 show estimates from proportional (logarithmic) models. For each model, the results are shown with controls for day of week and public holidays by gender (Columns 1 and 4), without these controls (Columns 2 and 5), and then with controls but using a sample including only weekdays (Columns 3 and 6).

The results in Table 2 show that both men and women increase donation attempts in response to the Bushfires, but the increase for females is larger. Specifically, the estimates in Column 1 show that on average, including weekends, males attempted to donate 292, 80 and 27 additional times per day within 1 week, 2-4 weeks and 5-8 weeks after the Bushfires occurred, respectively. The estimates further show that women increased donation attempt rates even more than men, with an extra increase for females of 332, 215 and 52 additional attempts per day in the week, 2-4 weeks and 5-8 weeks after the Bushfires. For males, only 
the changes within 1 week and 2-4 weeks are statistically significant, while the additional female response is significant at each time window.

Estimating the model without controls (Column 2) yields very similar point estimates, largely due to the day of week composition being identical during the control and bushfire periods. Without controls, the estimated bushfire effects are again large and positive, but are largely rendered statistically insignificant as removing the controls reduces precision and yields large standard errors. ${ }^{27}$ Restricting the sample to weekdays (Column 3) produces somewhat larger bushfire effects than in Column 1, an artefact of donation activity being concentrated in weekdays.

Table 2: Daily Donation Attempts - All Donors

\begin{tabular}{|c|c|c|c|c|c|c|}
\hline \multirow[b]{2}{*}{ Sample } & \multicolumn{3}{|c|}{ Linear: Attempts } & \multicolumn{3}{|c|}{ Proportional: Ln Attempts } \\
\hline & All days & All days & Weekdays & All days & All days & Weekdays \\
\hline \multicolumn{7}{|l|}{ Male Bushfire Effects } \\
\hline $\begin{array}{l}\text { BF Year * } \\
1^{\text {st }} \text { Week After }\end{array}$ & $\begin{array}{l}291.59 * * * \\
(70.82)\end{array}$ & $\begin{array}{l}291.59 \\
(310.91)\end{array}$ & $\begin{array}{l}333.55 * * * \\
(53.07)\end{array}$ & $\begin{array}{l}0.544 * \\
(0.290)\end{array}$ & $\begin{array}{c}0.544 \\
(0.739)\end{array}$ & $\begin{array}{c}0.228 * * \\
(0.100)\end{array}$ \\
\hline $\begin{array}{l}\text { BF Year * } \\
\text { 2-4 Weeks After }\end{array}$ & $\begin{array}{l}80.47 * * \\
(35.00)\end{array}$ & $\begin{array}{c}80.47 \\
(192.23)\end{array}$ & $\begin{array}{c}121.82 * * * \\
(33.31)\end{array}$ & $\begin{array}{l}-0.018 \\
(0.182)\end{array}$ & $\begin{array}{l}-0.018 \\
(0.512)\end{array}$ & $\begin{array}{c}0.080 \\
(0.088)\end{array}$ \\
\hline $\begin{array}{l}\text { BF Year * } \\
5-8 \text { Weeks After }\end{array}$ & $\begin{array}{c}26.50 \\
(32.97)\end{array}$ & $\begin{array}{c}76.50 \\
(171.55)\end{array}$ & $\begin{array}{c}34.88 \\
(36.56)\end{array}$ & $\begin{array}{c}0.056 \\
(0.212)\end{array}$ & $\begin{array}{c}0.252 \\
(0.515)\end{array}$ & $\begin{array}{c}0.108 \\
(0.106)\end{array}$ \\
\hline \multicolumn{7}{|c|}{ Female Excess Bushfire Effects } \\
\hline $\begin{array}{l}\text { BF Year } * \text { Female } * \\
1^{\text {st }} \text { Week After }\end{array}$ & $\begin{array}{l}331.79 * * * \\
(72.27)\end{array}$ & $\begin{array}{c}331.79 * * * \\
(110.94)\end{array}$ & $\begin{array}{l}458.08 * * * \\
\quad(40.20)\end{array}$ & $\begin{array}{l}0.216^{* * * *} \\
(0.069)\end{array}$ & $\begin{array}{c}0.216^{* *} \\
(0.099)\end{array}$ & $\begin{array}{c}0.216^{* * * *} \\
(0.022)\end{array}$ \\
\hline $\begin{array}{l}\text { BF Year } * \text { Female } * \\
2-4 \text { Weeks After }\end{array}$ & $\begin{array}{c}214.50 * * * \\
(34.93)\end{array}$ & $\begin{array}{l}214.50 * * * \\
\quad(56.25)\end{array}$ & $\begin{array}{l}293.88 * * * \\
(34.72)\end{array}$ & $\begin{array}{l}0.240 * * * \\
(0.059)\end{array}$ & $\begin{array}{c}0.240 * * * \\
(0.074)\end{array}$ & $\begin{array}{c}0.177 * * * \\
(0.024)\end{array}$ \\
\hline $\begin{array}{l}\text { BF Year } * \text { Female * } \\
5-8 \text { Weeks After }\end{array}$ & $\begin{array}{c}52.49 * * * \\
(19.26)\end{array}$ & $\begin{array}{l}60.50^{*} \\
(36.32)\end{array}$ & $\begin{array}{c}66.55 * * * \\
(24.81)\end{array}$ & $\begin{array}{l}0.110 * * \\
(0.046)\end{array}$ & $\begin{array}{c}0.113 * * \\
(0.054)\end{array}$ & $\begin{array}{c}0.048 * * \\
(0.020)\end{array}$ \\
\hline Constant & $\begin{array}{c}902.11 * * * \\
(24.99)\end{array}$ & $\begin{array}{c}657.75 * * * \\
(72.66)\end{array}$ & $\begin{array}{c}854.57 * * * \\
(24.20)\end{array}$ & $\begin{array}{c}6.736^{* * * *} \\
(0.158)\end{array}$ & $\begin{array}{c}5.717 * * * \\
(0.276)\end{array}$ & $\begin{array}{c}6.967 * * * \\
(0.120)\end{array}$ \\
\hline R-Squared & 0.958 & 0.079 & 0.922 & 0.831 & 0.030 & 0.805 \\
\hline N (days by gender) & 504 & 504 & 360 & 504 & 504 & 360 \\
\hline \multicolumn{7}{|l|}{ Dummy Variables: } \\
\hline Year & YES & YES & YES & YES & YES & YES \\
\hline Date Window & YES & YES & YES & YES & YES & YES \\
\hline Day of Week & YES & NO & YES & YES & NO & YES \\
\hline Public Holiday & YES & NO & YES & YES & NO & YES \\
\hline Interactions by Gender & YES & YES & YES & YES & YES & YES \\
\hline
\end{tabular}

\footnotetext{
${ }^{27}$ Weekends have far fewer daily attempts than weekdays. This weekly pattern provides the majority of variation in the data; the total number of donors on a given day is predictable even if the identity of donors is mostly not. Indeed, $\mathrm{R}^{2}$ coefficients are 0.8-0.9 in models with these controls and below 0.1 in those without.
} 
The results for the proportional effects models in Columns 4-6 also show greater responsiveness by females to the bushfire, with the estimates for the additional female response being significantly positive in each specification; Column 4 indicates that female attempts increased 22, 24 and $11 \log$ points more than male attempts increased 1, 2-4 and 5-8 weeks after the bushfires. Otherwise, the proportional models exhibit a similar pattern to the linear models, except that the male response is only significant for 1 week after the bushfire.

\subsection{Model Estimates: Results by Latent Altruism}

To examine whether groups with lower latent levels of altruism (1) have a greater proportional response to the Bushfires and (2) whether this response is greater for females than males, Tables 3-5 present estimates disaggregating donors into ex ante specified categories defined by different levels of proxies for latent blood donation propensity. Table 3 groups donation attempts by the length of time since the donor last made an attempt, Table 4 groups attempts by the donor's prior number of lifetime attempts, and Table 5 groups attempts by the donor's number of attempts in the previous rolling year (i.e. from the same date in the previous year) for donors who had made their first ever donation attempt at least a year earlier. While these criteria are imperfect proxies for latent altruism, in each case there is a monotonic association between attempted donation intensity and the typical level of latent altruism at the group level, such that the groups with less recent previous attempts, fewer lifetime prior attempts, and fewer attempts in the prior year, are hypothesised to have greater proportional response and additional female proportional response to the bushfire. For consistency with the theoretical prediction of proportional effects, the logarithmic specification is used henceforth.

Tables 3-5 examine the bushfire effects on donations using a sample consisting of weekdays only. Weekends typically have comparatively small numbers of donations, and thus small random absolute changes produce substantial proportional volatility. Table 2 shows that inclusion of weekends in the sample increases coefficient standard errors markedly (comparing Columns 4 and 6) despite the larger sample size (504 versus 360 days), thus potentially obscuring the true phenomena. A priori, excluding weekends is unlikely to distort any true proportional effects of the bushfire upon donations for two reasons. First, during the pertinent 36 week sample, weekends constitute only 3.3\% (3.0\%) of donation attempts in non-bushfire (bushfire) periods. Hence any substantial proportional effects on donation attempts observed on weekdays cannot possibly be offset by the changes on weekends. Second, for weekend exclusion to meaningfully distort the results would require 
not only that substitution between donating on weekdays and weekends increased during the bushfire period, but also markedly differentially by gender, with females (relative to males) substituting from donating on weekends to weekdays. This occurrence seems very implausible, and indeed the results on the full sample (see Online Appendix A1) are generally consistent with those in Tables 3-5 once accounting for reduced precision of the estimates.

Table 3 presents the results grouping donation attempts by the time since the donor last donated. Column 1 shows the results for new donors (shown in Figure 4) who had never previously attempted to donate and Column 2 shows the results for donors who had not attempted to donate for at least two years. The results for these two groups are particularly pertinent since it is particularly implausible that the Blood Service manufactured a gender effect through policy choice by disproportionately soliciting females in either group in response to the Bushfires. This is implausible since the Blood Service deems donors who have not donated for at least two years as 'long-lapsed' and ceases to send them any normal marketing materials or any other normal communications. Columns 3, 4 and 5 include donors whose last attempt was 1 to 2 years ago, 6 to 12 months ago, and 3 to 6 months ago, respectively; thus Table 3 shows increasingly more recent (thus, more altruistic) donors moving from left to right.

The estimates in Column 1 show that the average effect of the disaster on the number of new donors is large for both genders (29-74 log points, or 34-109\% for males) and significantly larger for women than men, with female increases of 14-33 log points (15-39\%) larger magnitude than males, during all three time periods following the disaster. Column 2 shows similar results for long-lapsed donors; the increase in the number of returning longlapsed female donors in the first four weeks after the bushfires is 25-33 log points $(28-40 \%)$ larger than the increase for males, which is itself 52-82 log points (67-128\%) greater than the control period rate. However, as conjectured, as donors with more recent last attempts (i.e. higher intensity) are considered, the bushfire effects diminish. Among somewhat more recent donors whose last attempt was one to two years earlier (Column 3), females only donate significantly more than men for the period 2-4 weeks after the Bushfires, with smaller point estimates for each gender. For the donors who last donated 3 to 6 months prior to the Bushfires (Column 5), the only significant positive effect is the female response for the week immediately after the Bushfires, and at $13 \log$ points (14\%) the proportional effect is relatively small. Other point estimates are small and generally indistinguishable from zero. 
Table 3: Log Donation Attempts by Time Since Last Attempt

\begin{tabular}{|c|c|c|c|c|c|}
\hline & \multirow[b]{2}{*}{ New Donor } & \multicolumn{4}{|c|}{ Time Since Last Attempt } \\
\hline & & $2+$ Years & 1-2 Years & 6-12 Months & 3-6 Months \\
\hline \multicolumn{6}{|c|}{ Male Bushfire Effects } \\
\hline $\begin{array}{l}\text { BF Year * } \\
1^{\text {st }} \text { Week After }\end{array}$ & $\begin{array}{l}0.739 * * * \\
(0.110)\end{array}$ & $\begin{array}{l}0.822 * * * \\
(0.093)\end{array}$ & $\begin{array}{c}0.488 * * * \\
(0.103)\end{array}$ & $\begin{array}{l}0.180 * * \\
(0.071)\end{array}$ & $\begin{array}{l}-0.029 \\
(0.074)\end{array}$ \\
\hline $\begin{array}{l}\text { BF Year* } \\
2-4 \text { Weeks After }\end{array}$ & $\begin{array}{c}0.446^{* * *} \\
(0.103)\end{array}$ & $\begin{array}{c}0.515^{* * *} \\
(0.083)\end{array}$ & $\begin{array}{c}0.027 \\
(0.077)\end{array}$ & $\begin{array}{c}0.002 \\
(0.072)\end{array}$ & $\begin{array}{l}-0.126^{*} \\
(0.066)\end{array}$ \\
\hline $\begin{array}{l}\text { BF Year* } \\
5-8 \text { Weeks After }\end{array}$ & $\begin{array}{l}0.293 * * * \\
(0.110)\end{array}$ & $\begin{array}{l}0.211 * * * \\
(0.079)\end{array}$ & $\begin{array}{c}0.017 \\
(0.083)\end{array}$ & $\begin{array}{l}-0.026 \\
(0.082)\end{array}$ & $\begin{array}{l}-0.005 \\
(0.084)\end{array}$ \\
\hline \multicolumn{6}{|c|}{ Female Excess Bushfire Effects } \\
\hline $\begin{array}{l}\text { BF Year * Female * } \\
1^{\text {st }} \text { Week After }\end{array}$ & $\begin{array}{c}0.328 * * * \\
(0.053)\end{array}$ & $\begin{array}{c}0.334 * * * \\
(0.124)\end{array}$ & $\begin{array}{c}0.115 \\
(0.105)\end{array}$ & $\begin{array}{l}0.241 * * * \\
(0.068)\end{array}$ & $\begin{array}{l}0.131 * * \\
(0.051)\end{array}$ \\
\hline $\begin{array}{l}\text { BF Year * Female * } \\
2-4 \text { Weeks After }\end{array}$ & $\begin{array}{c}0.332 * * * \\
(0.052)\end{array}$ & $\begin{array}{l}0.248^{* * * *} \\
(0.093)\end{array}$ & $\begin{array}{c}0.227 * * * \\
(0.079)\end{array}$ & $\begin{array}{l}0.098 * \\
(0.057)\end{array}$ & $\begin{array}{c}0.060 \\
(0.045)\end{array}$ \\
\hline $\begin{array}{l}\text { BF Year * Female * } \\
5-8 \text { Weeks After }\end{array}$ & $\begin{array}{c}0.139 * * * \\
(0.047)\end{array}$ & $\begin{array}{c}0.045 \\
(0.085)\end{array}$ & $\begin{array}{l}-0.059 \\
(0.068)\end{array}$ & $\begin{array}{c}0.053 \\
(0.054)\end{array}$ & $\begin{array}{c}0.011 \\
(0.038)\end{array}$ \\
\hline Constant & $\begin{array}{l}5.198 * * * \\
(0.089)\end{array}$ & $\begin{array}{c}3.174 * * * \\
(0.065)\end{array}$ & $\begin{array}{c}3.978 * * * \\
(0.078)\end{array}$ & $\begin{array}{c}4.670 * * * \\
(0.075)\end{array}$ & $\begin{array}{c}5.535 * * * \\
(0.093)\end{array}$ \\
\hline R Squared & 0.814 & 0.866 & 0.826 & 0.846 & 0.844 \\
\hline $\mathrm{N}$ (days by gender) & 360 & 360 & 360 & 360 & 360 \\
\hline
\end{tabular}

All regressions include dummy variables for year, date windows, days of week, public holidays and interact gender with these controls. Robust standard errors clustered by date in parentheses. Significance levels: *** $\mathrm{p}<.01 ;{ }^{* *} \mathrm{p}<.05,{ }^{*} \mathrm{p}<.10$

We now formally test whether the overall bushfire effect (that is, the effect for men) and the excess female effect reported in Table 3 are larger for the groups associated with lower levels of altruism than higher altruism groups. This is a test of whether the estimates across columns (i.e., groups with different levels of latent altruism) are significantly different from each other. $^{28}$

Table 3a presents the critical results from these tests of whether the bushfire effect coefficients for group $i$ exceed the respective coefficients of group $j$, for each of the categories of time since a donor's previous attempt, where $j$ is the group with higher previous donation intensity. Formally, we (separately) test the hypotheses that $\beta_{i, b}-\beta_{j, b}>0$ and $\beta_{i, b}^{f}-\beta_{j, b}^{f}>0, \forall\{i, j>i\} \in G$. While this comparison could in principle be undertaken with any of the time windows in the model, for simplicity the model is reduced to have only 1-4 weeks and 5-8 weeks post-Bushfire date windows, and tests are performed on the bushfire

\footnotetext{
${ }^{28}$ To conduct this test, we included the data from all of the groups and estimated the model including dummy variables for each group $G$, as well as all of the interactions between each group and all of the other variables in the model. To test all pairwise effects, this is done $G$ times, taking each group as the omitted dummy in turn.
} 
effect coefficients for the 1-4 week window, since this is the time horizon where donor response is overwhelmingly concentrated.

The results in Table 3a confirm, as theoretically predicted, that the (proportional) bushfire effects on men and the excess effects on women are in general significantly larger for lower altruism groups than higher altruism groups, although for adjacent groups the differences are often not significant. For example, male donors who had either previously never donated or who had not donated in at least two years prior to the bushfire were highly significantly $(\mathrm{p}<$ .01) more responsive to the bushfire than male donors who had most recently donated 1-2 years, 6-12 months or 3-6 months prior to the bushfire, while the excess female response is also highly significantly $(\mathrm{p}<.01)$ larger for women who had never donated before compared to women who had most recently donated 6-12 and 3-6 months prior to the bushfire.

Table 3a: Bushfire Effect Differences for Time Since Last Attempt Categories

\begin{tabular}{lcccc|cccc}
\hline \hline & \multicolumn{3}{c}{ Male Bushfire Effects } & \multicolumn{3}{c}{ Female Excess Bushfire Effects } \\
\cline { 2 - 9 } & 2+ & $\mathbf{1 - 2}$ & $\mathbf{6 - 1 2}$ & $\mathbf{3 - 6}$ & $\mathbf{2 +}$ & $\mathbf{1 - 2}$ & $\mathbf{6 - 1 2}$ & $\mathbf{3 - 6}$ \\
& Years & Years & Months & Months & Years & Years & Months & Months \\
New Donor & $(0.471)$ & 0.000 & 0.000 & 0.000 & 0.551 & 0.109 & 0.001 & 0.000 \\
2+ Years & & 0.000 & 0.000 & 0.000 & & 0.554 & 0.193 & 0.040 \\
1-2 Years & & 0.208 & 0.003 & & & 0.473 & 0.109 \\
6-12 Months & & & 0.008 & & & & 0.425 \\
\hline \hline
\end{tabular}

Two sided p-value for test that coefficient on (male or excess female, respectively) bushfire effect for 1-4 weeks after Bushfire is greater for lower donation intensity group than higher donation intensity group. Parentheses indicate negative difference coefficient. Calculated from regression with dummies for windows of 1-4 weeks and 5-8 weeks post-Bushfire, using robust standard errors clustered by date.

Table 4 disaggregates the data by the total number of attempts someone had previously made as a different perspective on latent donation propensity. For comparison, the first column is identical to the first column in Table 3 and again shows new donors. The remaining columns show donation attempts for weekdays in the 36 week window by donors who had made one, two, three-four, five-nine and 10 or more lifetime previous donations attempts. Here, the observed changes are far less substantial than when grouping by time since the last attempt, but exhibit similar patterns. The only significant increases for males occur in the first week after the Bushfires, with bushfire effects of $24 \log$ points $(27 \%)$ for first return donors (Column 2) and $22 \log$ points (25\%) for donors with 2 prior attempts (Column 3). All other estimates for males are insignificant and close to zero. Across groups, females consistently exhibit larger proportional responses than males. The additional increase in attempts by female donors with just one past donation attempt is statistically significant at 
15-22 log points (16-24\%) in the first four weeks after the Bushfires. Further, significant additional increases in either or both of the first week and 2-4 weeks after the Bushfires are observed for female donors with two to nine previous attempts (Columns 3-5). Again, consistent with the theoretical conjecture, both the magnitude and statistical significance of changes diminish as the number of prior attempts for a donor increases, and the additional female effects for donors with at least 10 prior attempts are small and insignificant. ${ }^{29}$

Table 4: Log Donation Attempts by Number of Lifetime Previous Attempts

\begin{tabular}{|c|c|c|c|c|c|c|}
\hline & \multirow[b]{2}{*}{ New Donor } & \multicolumn{5}{|c|}{ Lifetime Previous Attempts } \\
\hline & & 1 Attempt & 2 Attempts & 3-4 Attempts & 5-9 Attempts & 10+ Attempts \\
\hline \multicolumn{7}{|c|}{ Male Bushfire Effects } \\
\hline $\begin{array}{l}\text { BF Year * } \\
1^{\text {st }} \text { Week After }\end{array}$ & $\begin{array}{c}0.739 * * * \\
(0.110)\end{array}$ & $\begin{array}{c}0.238 * * * \\
(0.076)\end{array}$ & $\begin{array}{c}0.222 * * * \\
(0.084)\end{array}$ & $\begin{array}{c}0.097 \\
(0.066)\end{array}$ & $\begin{array}{l}-0.016 \\
(0.065)\end{array}$ & $\begin{array}{l}-0.038 \\
(0.068)\end{array}$ \\
\hline $\begin{array}{l}\text { BF Year* } \\
\text { 2-4 Weeks After }\end{array}$ & $\begin{array}{c}0.446^{* * *} \\
(0.103)\end{array}$ & $\begin{array}{l}-0.019 \\
(0.068)\end{array}$ & $\begin{array}{c}0.047 \\
(0.058)\end{array}$ & $\begin{array}{l}-0.069 \\
(0.055)\end{array}$ & $\begin{array}{l}-0.051 \\
(0.062)\end{array}$ & $\begin{array}{l}-0.035 \\
(0.055)\end{array}$ \\
\hline $\begin{array}{l}\text { BF Year* } \\
5-8 \text { Weeks After }\end{array}$ & $\begin{array}{c}0.293 * * * \\
(0.110)\end{array}$ & $\begin{array}{c}0.037 \\
(0.082)\end{array}$ & $\begin{array}{c}0.084 \\
(0.078)\end{array}$ & $\begin{array}{l}-0.021 \\
(0.069)\end{array}$ & $\begin{array}{l}-0.016 \\
(0.075)\end{array}$ & $\begin{array}{l}-0.011 \\
(0.072)\end{array}$ \\
\hline \multicolumn{7}{|c|}{ Female Excess Bushfire Effects } \\
\hline $\begin{array}{l}\text { BF Year * Female * } \\
1^{\text {st }} \text { Week After }\end{array}$ & $\begin{array}{c}0.328 * * * \\
(0.053)\end{array}$ & $\begin{array}{c}0.149 * * * \\
(0.055)\end{array}$ & $\begin{array}{c}0.102 \\
(0.064)\end{array}$ & $\begin{array}{c}0.163 * * * \\
(0.054)\end{array}$ & $\begin{array}{c}0.201 * * * \\
(0.037)\end{array}$ & $\begin{array}{c}0.067 \\
(0.083)\end{array}$ \\
\hline $\begin{array}{l}\text { BF Year * Female * } \\
2-4 \text { Weeks After }\end{array}$ & $\begin{array}{c}0.332 * * * \\
(0.052)\end{array}$ & $\begin{array}{c}0.215^{* * *} \\
(0.055)\end{array}$ & $\begin{array}{l}0.121 * * \\
(0.061)\end{array}$ & $\begin{array}{l}0.113 * * \\
/(0.046)\end{array}$ & $\begin{array}{c}0.048 \\
(0.041)\end{array}$ & $\begin{array}{c}0.020 \\
(0.049)\end{array}$ \\
\hline $\begin{array}{l}\text { BF Year * Female * } \\
5-8 \text { Weeks After }\end{array}$ & $\begin{array}{c}0.139 * * * \\
(0.047)\end{array}$ & $\begin{array}{c}0.031 \\
(0.050)\end{array}$ & $\begin{array}{c}0.041 \\
(0.059)\end{array}$ & $\begin{array}{c}0.013 \\
(0.048)\end{array}$ & $\begin{array}{l}-0.001 \\
(0.037)\end{array}$ & $\begin{array}{l}-0.084 \\
(0.054)\end{array}$ \\
\hline Constant & $\begin{array}{c}5.198 * * * \\
(0.089)\end{array}$ & $\begin{array}{c}4.968 * * * \\
(0.073)\end{array}$ & $\begin{array}{c}4.763 * * * \\
(0.076)\end{array}$ & $\begin{array}{c}5.136 * * * \\
(0.072)\end{array}$ & $\begin{array}{c}5.441 * * * \\
(0.079)\end{array}$ & $\begin{array}{c}4.946 * * * \\
(0.086)\end{array}$ \\
\hline R Squared & 0.814 & 0.838 & 0.865 & 0.884 & 0.875 & 0.926 \\
\hline $\mathrm{N}$ (days by gender) & 360 & 360 & 360 & 360 & 360 & 360 \\
\hline
\end{tabular}

All regressions include dummy variables for year, date windows, days of week, public holidays and gender interacted with these controls. Robust standard errors clustered by date in parentheses. Significance levels: *** $p<.01 ; * * p<.05,{ }^{*} p<.10$

Table 4a, similar to Table 3a, reports p-values for tests of whether the bushfire effects are larger on groups of donors with fewer previous lifetime donation attempts. These results again confirm that the bushfire effects on male and excess female donation rates are significantly larger for the lower altruism groups than the higher altruism groups, although

\footnotetext{
${ }^{29}$ A possible concern with the results for high frequency donors is that sophisticated donors may have been aware that the Bushfire did not meaningfully increase demand for blood products, or even anticipated an oversupply. Such donors, who are more likely to be high frequency donors, could have responded to this oversupply by temporarily halting or delaying their donations, distorting results and obscuring increases in donation attempt rates by less sophisticated donors. However, in additional analysis (see Online Appendix A3) of the distribution of time between donor attempts, no evidence of economically significant crowding out of sophisticated donors in response to the Bushfires was found.
} 
there are no significant overall differences within the subgroups with 3 or more lifetime prior attempts.

Table 4a: Bushfire Effect Differences for Number of Lifetime Previous Attempts Categories

\begin{tabular}{lccccc|ccccc}
\hline \hline & & \multicolumn{3}{c|}{ Male Bushfire Effects } & \multicolumn{4}{c}{ Female Excess Bushfire Effects } \\
\cline { 2 - 7 } & $\mathbf{1}$ & $\mathbf{2}$ & $\mathbf{3 - 4}$ & $\mathbf{5 - 9}$ & $\mathbf{1 0 +}$ & $\mathbf{1}$ & $\mathbf{2}$ & $\mathbf{3 - 4}$ & $\mathbf{5 - 9}$ & $\mathbf{1 0 +}$ \\
New Donor & 0.000 & 0.000 & 0.000 & 0.000 & 0.000 & 0.033 & 0.004 & 0.000 & 0.000 & 0.000 \\
$\mathbf{1}$ Attempt & & $(0.463)$ & 0.166 & 0.082 & 0.179 & & 0.242 & 0.249 & 0.079 & 0.027 \\
2 Attempts & & & 0.042 & 0.020 & 0.019 & & & $(0.894)$ & 0.685 & 0.288 \\
3-4 Attempts & & & 0.760 & 0.876 & & & & 0.502 & 0.167 \\
5-9 Attempts & & & & $(0.866)$ & & & & & 0.374 \\
\hline \hline
\end{tabular}

Two sided p-value for test that coefficient on (male or excess female, respectively) bushfire effect for 1-4 weeks after Bushfire is greater for lower donation intensity group than higher donation intensity group. Parentheses indicate negative difference coefficient. Calculated from regression with dummies for windows of 1-4 weeks and 5-8 weeks post-Bushfire, using robust standard errors clustered by date.

As a final perspective on donors with different levels of altruism, Table 5 disaggregates the data by the number of attempts someone made in the past year conditional upon having begun donating at least a year prior and having an attempt in the past two years. The columns show results for donors who had made zero (but by definition, not new donors), one, two, and three or more donations in the past year prior to the attempt during our sample period. For donors with no attempts in the previous year (which by construction does not include longlapsed donors), an increase for males, and an additional increase for females, are observed, although not at all date windows. However, for donors with one attempt in the prior year, the only significant result is a positive change of $28 \log$ points (33\%) for females compared to males in the first week after the bushfire. There are no positive significant effects for males or additional effects for females for donors with two or more donations in the prior year. As larger changes are again found for less intense donors, this is again consistent with the conjecture, but also suggests that the criterion of attempts in the prior year is less successful at identifying donors of different latent donation propensities.

Table 5a provides the formal tests of whether the bushfire effect coefficients for both males, and females in excess of males, are greater in donors with fewer donations in the past year. It shows that donors with no attempts in the previous year (but an attempt within two years previous) respond significantly more than those with at least one donation in the past year, but there are few significant differences among donors with 1, 2 or $3+$ attempts within the past year. 
Table 5: Log Donation Attempts by Number of Donation Attempts in Past Year

\begin{tabular}{|c|c|c|c|c|}
\hline & \multicolumn{4}{|c|}{ Number of Donation Attempts in Past Year } \\
\hline & 0 Attempts & 1 Attempt & 2 Attempts & 3+ Attempts \\
\hline \multicolumn{5}{|l|}{ Male Bushfire Effects } \\
\hline $\begin{array}{l}\text { BF Year * } \\
1^{\text {st }} \text { Week After }\end{array}$ & $\begin{array}{c}0.495 * * * \\
(0.103)\end{array}$ & $\begin{array}{c}0.103 \\
(0.074)\end{array}$ & $\begin{array}{c}0.010 \\
(0.077)\end{array}$ & $\begin{array}{l}-0.092 \\
(0.062)\end{array}$ \\
\hline $\begin{array}{l}\text { BF Year* } \\
2-4 \text { Weeks After }\end{array}$ & $\begin{array}{c}0.036 \\
(0.077)\end{array}$ & $\begin{array}{l}-0.061 \\
(0.071)\end{array}$ & $\begin{array}{l}-0.031 \\
(0.055)\end{array}$ & $\begin{array}{l}-0.073 \\
(0.057)\end{array}$ \\
\hline $\begin{array}{l}\text { BF Year* } \\
5-8 \text { Weeks After }\end{array}$ & $\begin{array}{c}0.023 \\
(0.082)\end{array}$ & $\begin{array}{l}-0.111 \\
(0.080)\end{array}$ & $\begin{array}{c}0.002 \\
(0.070)\end{array}$ & $\begin{array}{l}-0.031 \\
(0.075)\end{array}$ \\
\hline \multicolumn{5}{|c|}{ Female Excess Bushfire Effects } \\
\hline $\begin{array}{l}\text { BF Year } * \text { Female } * \\
1^{\text {st }} \text { Week After }\end{array}$ & $\begin{array}{c}0.110 \\
(0.105)\end{array}$ & $\begin{array}{c}0.284 * * * \\
(0.070)\end{array}$ & $\begin{array}{c}0.086 \\
(0.071)\end{array}$ & $\begin{array}{c}0.042 \\
(0.043)\end{array}$ \\
\hline $\begin{array}{l}\text { BF Year * Female * } \\
\text { 2-4 Weeks After }\end{array}$ & $\begin{array}{c}0.216^{* * * *} \\
(0.079)\end{array}$ & $\begin{array}{c}0.077 \\
(0.066)\end{array}$ & $\begin{array}{c}0.039 \\
(0.047)\end{array}$ & $\begin{array}{l}-0.017 \\
(0.041)\end{array}$ \\
\hline $\begin{array}{l}\text { BF Year * Female * } \\
5-8 \text { Weeks After }\end{array}$ & $\begin{array}{l}-0.064 \\
(0.068)\end{array}$ & $\begin{array}{c}0.025 \\
(0.063)\end{array}$ & $\begin{array}{c}0.014 \\
(0.052)\end{array}$ & $\begin{array}{c}-0.101^{* * * *} \\
(0.039)\end{array}$ \\
\hline Constant & $\begin{array}{c}3.977 * * * \\
(0.078)\end{array}$ & $\begin{array}{c}4.554 * * * \\
(0.070)\end{array}$ & $\begin{array}{c}4.678 * * * \\
(0.076)\end{array}$ & $\begin{array}{l}5.581 * * * \\
(0.084)\end{array}$ \\
\hline R Squared & 0.826 & 0.872 & 0.879 & 0.915 \\
\hline $\mathrm{N}$ (days by gender) & 360 & 360 & 360 & 360 \\
\hline
\end{tabular}

Conditional on beginning to donate more than one year ago, and having attempt within past two years. All regressions include dummy variables for year, date windows, days of week, public holidays and gender by these controls. Robust standard errors clustered by date in parentheses. Significance levels: ${ }^{* * *} \mathrm{p}<.01 ; * * \mathrm{p}<.05,{ }^{*} \mathrm{p}<.10$.

Table 5a: Bushfire Effect Differences for Donation Attempts in Past Year Categories

\begin{tabular}{lccc|ccc}
\hline \hline & \multicolumn{3}{c|}{ Male Bushfire Effects } & \multicolumn{2}{c}{ Female Excess Bushfire Effects } \\
\cline { 2 - 4 } & 1 in Year & 2 in Year & 3+ in Year & 1 in Year & 2 in Year & 3+ in Year \\
0 Attempts in Year & 0.025 & 0.020 & 0.003 & 0.541 & 0.064 & 0.020 \\
1 Attempt in Year & & 0.994 & 0.323 & & 0.308 & 0.067 \\
2 Attempts in Year & & & 0.221 & & 0.372 \\
\hline \hline
\end{tabular}

Two sided p-value for test that coefficient on (male or excess female, respectively) bushfire effect for 1-4 weeks after Bushfire is greater for lower donation intensity group than higher donation intensity group. Parentheses indicate negative difference coefficient. Calculated from regression with dummies for windows of 1-4 weeks and 5-8 weeks post-Bushfire, using robust standard errors clustered by date.

\subsection{Discussion}

Across the three proxies for latent altruism, the observed changes in donation behaviour following the Bushfires match the key stylised predictions of the theoretical model presented in Section 2 of differential variance in latent altruism by gender. First, the increase in donation attempts caused by the Bushfires was larger in proportional terms among donor 
groups with lower levels of donation intensity, and thus implicitly lower latent altruism. This is consistent with the idiosyncratic donation propensity shock $\varepsilon_{i t}$ having an increasing hazard rate, and thus provides further credence for this theoretical assumption. Second, the proportional increase in donation attempts by donors within each group is typically larger for females than males; the excess female response coefficients are overwhelmingly positive even if they are not always statistically significant. Finally, consistent with our theoretical conjecture, the magnitude of excess female response is greatest amongst groups with lower latent altruism, and in general falls as the intensity of donors' previous donation history and donation recency increases. Accordingly, these results provide evidence that is consistent with the hypothesis that women have a narrower and more peaked latent distribution of altruism than men. ${ }^{30} \mathrm{~A}$ natural caveat to this is that these observations are restricted to the behaviour of actual donors, who are predominantly located in the right tail of the altruism distribution. Hence while the observed results are suggestive, they are not sufficient alone to conclude that differences in the altruism by gender hold across the full support of the distribution.

\section{5. $\quad$ Summary}

This paper finds that both males and females respond to a natural disaster by increasing their donation attempt rates, and that the proportional increase is larger among females. Moreover, it finds that both the proportional change in donation attempts for both genders, and the magnitude of the gender difference, are larger for categories of donors who were ex ante categorized based on past donation behaviour as having lower latent altruism. Together, these facts are consistent with the hypothesis that women have a narrower and more peaked latent distribution of altruism. We observed that a donor's time since last donation attempt and number of prior donation attempts are useful proxies of latent altruism, allowing both of these predicted phenomena to be identified. In particular, the time since a donor's last attempt proved a particularly sharp distinguishing measure, perhaps since latent altruism may drift over time. For instance, someone who has donated only once, but in the past few months, may presently have higher latent altruism than someone who has donated many times, but not in the past two years.

\footnotetext{
${ }^{30}$ Other events that shock donation propensity, such as the September 11 terrorist attacks and the Bali Bombings, yield changes in blood donation rates that are consistent with these Bushfire results, and thus further supports this theory. While our data from Australia blood donors around the dates of these events is much more limited, on both occasions donation rates jump sharply, and increase by a larger amount for new donors compared to existing donors. Further, the proportional female changes are greater than changes for males, and the excess female response is greater among more marginal donors (new donors). Results are omitted here but are available online, see Online Appendix A5 and Online Appendix A6 for details.
} 
Our results suggest several fruitful directions for further understanding gender differences in altruism. First, while our results extend the conclusions drawn from DellaVigna et al. (2013) to a novel context and to a shock to the benefits of volunteering, and establish effects at different margins in the altruism distribution, more contexts and different cultural populations would further enlighten the robustness of the results. Second, further development in theory to tie the growing empirical evidence to evolutionary, sociological or psychological theories of gender differences in altruism could sharpen the current predictions.

The gender differences in the latent distribution for altruism suggest that policy-makers and charitable organizations may want to explore differential strategies toward fundraising and volunteer recruitment for men and women. For instance, as we find here, strategies that have a temporary increase in providing altruistic benefits will successfully attract men, but will attract even more women. Our model and results may also partially explain disparities in female and male volunteerism that could emerge from a greater responsiveness to need without any targeted attempts by organizations.

More generally, our results stress the importance of considering the margin on which treatment effects are being examined. In our context, where donors are in the far right tail of the altruism distribution, a theory of differential variance by gender leads to greater female response to shocks. This same theory also predicts that the gender differences will depend on the exact location of the marginal donor considered. This suggests the possibility that consideration of the exact point on the distribution in which treatments are examined may help to reconcile inconsistent gender difference findings across contexts. 


\section{References}

Andreoni, James, and Lise Vesterlund (2001), "Which is the Fair Sex? Gender Differences in Altruism," The Quarterly Journal of Economics, 116:1, 293-312.

Croson, Rachel, and Uri Gneezy (2009). "Gender Differences in Preferences," Journal of Economic Literature 47:2, 1-27.

DellaVigna, Stefano, John List, Ulrike Malmendier and Gautam Rao (2013). "The Importance of Being Marginal: Gender Differences in Generosity," American Economic Review Papers and Proceedings 103, 586-590.

Eckel, Catherine, Philip Grossman and Angela Milano (2007). "Is More Information Always Better? An Experimental Study of Charitable Giving and Hurricane Katrina," Southern Economic Journal 74:2, 388411.

Garbarino, Ellen, Robert Slonim and Carmen Wang (2013). "The Multidimensional Effects of a Small Gift: Evidence from a Natural Field Experiment," Economics Letters, 120, 83-86.

Li, Yiyuan, Li Hong, Jean Decty and Kang Lee (2013). "Experiencing a Natural Disaster Alters Children's Altruistic Giving," Psychological Science 0956797613479975, September 13, 2013.

List, John (2011). "The Market for Charitable Giving”, Journal of Economic Perspectives 25:2, 157-180.

Slonim, Robert, Carmen Wang and Ellen Garbarino (2014). "The Market for Blood," Journal of Economic Perspectives, 28:2, 177-196.

Warfield, Samantha (2013). "New Federal Report Finds 1 in 4 Americans Volunteer," Corporation for National \& Community Service. 